\title{
EROI for the production of methane from hydrates by hot water injection
}

\author{
R. C. Callarotti \\ Universidad del Turabo, Gurabo, Puerto Rico
}

\begin{abstract}
We model the heating of submarine methane hydrate deposits located at depths between 1000 and 1500 meters, when the heating is supplied by hot water flowing through a horizontal pipe located inside the reservoir. The hot water is supplied as heat exchanger output of a combined cycle power plant and then pumped at a given velocity into the horizontal pipe. By means of the enthalpy method we determine the time dependent heating of the hydrates and the amount of their melted volume. The partial energy efficiency of this process (EROI) is determined as the ratio of the equivalent energy of the gas produced to the kinetic energy required for the flow of the water at a given speed through the heating pipe. This efficiency is found to vary from a value of 20 at the beginning of the heating to a value of 2.8 after 50 years of operation. The EROI is found to be to be independent of the length of the horizontal well.

Keywords: EROI, methane hydrate production, convective heat transfer, moving boundary problems, enthalpy method.
\end{abstract}

\section{Introduction}

Methane hydrates are water-methane compounds which are present under the proper temperature and pressure conditions either at the bottom of the sea close to continental shelves or in the subsoil (Sloan [1] and Carroll [2]). They are important due to the very large amounts of methane they contain (Demirbas [3]). By 1999 Japan had already started very significant efforts to produce gas from land and oceanic deposits, and recent research has been directed to the production of methane hydrates via heated horizontal wells (Yamakawa et al. [4]). Hot water from the heat exchangers of a floating power plant is injected into the horizontal pipe inserted through the reservoir. 
In view of the importance of the energy efficiency for the production of methane from hydrates we began by extending our work on the electromagnetic heating of petroleum (Callarotti [7]) to the low frequency $(50-60 \mathrm{~Hz})$ electrical heating of methane hydrate reservoirs $[9,10]$.

In the present work we determine the partial energy return on energy invested (EROI) for the Japanese scheme for the production of methane from hydrates by hot water flowing through a horizontal well. The EROI that we obtain is only partial as we only consider the ratio of the energy equivalent of the methane hydrate melted volume divided by the kinetic energy required to inject the water at a given velocity. We assume that the hot water is a free by product of a co-generation power plant (under the Japanese scheme this will be a floating power plant, close by the methane hydrate deposits). Also, our EROI calculation will not consider the energy required in the construction of the different system components. The system considered is shown on Figure 1.

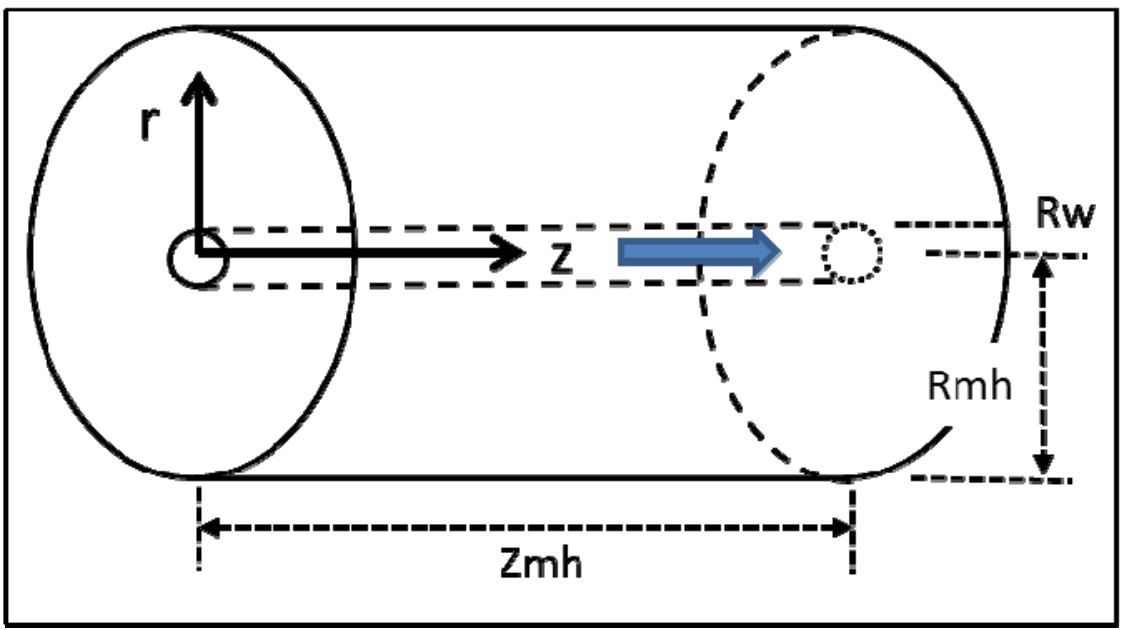

Figure 1: Geometry of the system considered. The arrow indicates the flow path for the hot water flowing through the hydrate reservoir.

In our model the reservoir is modeled as a cylinder (length $\mathrm{Zmh}$ and outer radius $\mathrm{Rmh}$ ), with a cylindrical well (radius $\mathrm{Rw}$ ). We chose this cylindrical geometry so that we can solve numerically the heat transfer equations in cylindrical coordinates, with the corresponding reduction in matrix sizes from the three dimensional $\mathrm{x}, \mathrm{y}, \mathrm{z}$ formulation. The heat transfer equations that define the temperatures in the well $\mathrm{T}_{\mathrm{w}}(\mathrm{r}, \mathrm{z})$, and in the reservoir $\mathrm{T}(\mathrm{r}, \mathrm{z})$, are:

$$
\frac{\partial^{2} \mathrm{~T}_{\mathrm{w}}(\mathrm{r}, \mathrm{z})}{\partial \mathrm{r}^{2}}+\frac{1}{\mathrm{r}} \frac{\partial \mathrm{T}_{\mathrm{w}}(\mathrm{r}, \mathrm{z})}{\partial \mathrm{r}}+\frac{\partial^{2} \mathrm{~T}_{\mathrm{w}}(\mathrm{r}, \mathrm{z})}{\partial \mathrm{z}^{2}}-\frac{\mathrm{v}(\mathrm{r})}{\kappa_{\mathrm{w}}} \frac{\partial \mathrm{T}_{\mathrm{w}}(\mathrm{r}, \mathrm{z})}{\partial \mathrm{z}}=\frac{1}{\kappa_{\mathrm{w}}} \frac{\partial \mathrm{T}_{\mathrm{w}}(\mathrm{r}, \mathrm{z})}{\partial \mathrm{t}}
$$

where $\kappa_{w}$ is the thermal diffusivity of water and $v(r)$ is the velocity in the well in the $+\mathrm{z}$ direction. In the reservoir the pertinent equation for the hydrate region is: 


$$
\frac{\partial^{2} \mathrm{~T}(\mathrm{r}, \mathrm{z})}{\partial \mathrm{r}^{2}}+\frac{1}{\mathrm{r}} \frac{\partial \mathrm{T}(\mathrm{r}, \mathrm{z})}{\partial \mathrm{r}}+\frac{\partial^{2} \mathrm{~T}(\mathrm{r}, \mathrm{z})}{\partial \mathrm{z}^{2}}=\frac{1}{\kappa_{\mathrm{mh}}} \frac{\partial \mathrm{T}(\mathrm{r}, \mathrm{z})}{\partial \mathrm{t}}
$$

where $\kappa_{\mathrm{mh}}$ is the thermal diffusivity of the methane hydrate and $(\mathrm{r}, \mathrm{z})$ correspond to coordinates for a point where $\mathrm{T}(\mathrm{r}, \mathrm{z}) \leq \mathrm{T}_{0}$ (temperature less than or equal to the hydrate melting temperature $\mathrm{T}_{0}$ which we take as $20 \mathrm{C}$ for the depths considered. If we are in a zone where the temperature is greater than the hydrate melting temperature then the pertinent reservoir equation is:

$$
\frac{\partial^{2} \mathrm{~T}(\mathrm{r}, \mathrm{z})}{\partial \mathrm{r}^{2}}+\frac{1}{\mathrm{r}} \frac{\partial \mathrm{T}(\mathrm{r}, \mathrm{z})}{\partial \mathrm{r}}+\frac{\partial^{2} \mathrm{~T}(\mathrm{r}, \mathrm{z})}{\partial \mathrm{z}^{2}}=\frac{1}{\kappa_{\mathrm{w}}} \frac{\partial \mathrm{T}(\mathrm{r}, \mathrm{z})}{\partial \mathrm{t}}
$$

As described by Callarotti [6] eqns (2)-(3) are solved using the enthalpy method. At the surface pipe-reservoir the temperature continuity is obtained by applying the following boundary condition:

$$
\mathrm{T}_{\mathrm{w}}\left(\mathrm{r}_{\mathrm{w}}, \mathrm{z}\right)=\mathrm{T}\left(\mathrm{r}_{\mathrm{w}}, \mathrm{z}\right)
$$

When the volume considered is discretized $(\Delta \mathrm{r}, \Delta \mathrm{z})$ the finite difference expression for eqn (1) becomes:

$$
\begin{gathered}
\frac{T_{w i+1, j}^{k}-2 T_{w i, j}^{k}+T_{w i-1, j}^{k}}{(\Delta r)^{2}}+\frac{T_{w i+1, j}^{k}-T_{w i, j}^{k}}{i(\Delta r)^{2}}+\frac{T_{w i, j+1}^{k}-2 T_{w i, j}^{k}+T_{w i, j-1}^{k}}{(\Delta z)^{2}} \\
-\frac{v(i \Delta r)}{\kappa_{w}} \frac{T_{w i, j+1}^{k}-T_{w i, j}^{k}}{\Delta z}=\frac{1}{\kappa_{w}} \frac{T_{w i, j}^{k}-T_{w i, j}^{k}}{\Delta t}
\end{gathered}
$$

\section{Stability of the solutions}

The stability of the solution of the previous equation in time can be controlled by the proper choice of the time interval but stability can only be viable for small values of the velocity in the pipe. Figure 2 shows the solutions obtained for $\mathrm{T}_{\mathrm{w}}(\mathrm{r}, \mathrm{z})$, the temperature along a cylinder of radius $0.5 \mathrm{~m}$, length $400 \mathrm{~m}$, with boundary conditions given by:

$$
\mathrm{T}_{\mathrm{w}}\left(\mathrm{r} \leq \mathrm{r}_{\mathrm{w}}, \mathrm{z}=0\right)=200 \mathrm{C} \quad \mathrm{T}_{\mathrm{w}}\left(\mathrm{r}_{\mathrm{w}}, \mathrm{z}\right)=2 \mathrm{C}
$$

As we can see from the Figure 3, as the velocity along the pipe is increased, the temperature along the pipe tends to a linear dependence on the distance along the well, and the results show oscillations, indicating the approach of instability. 


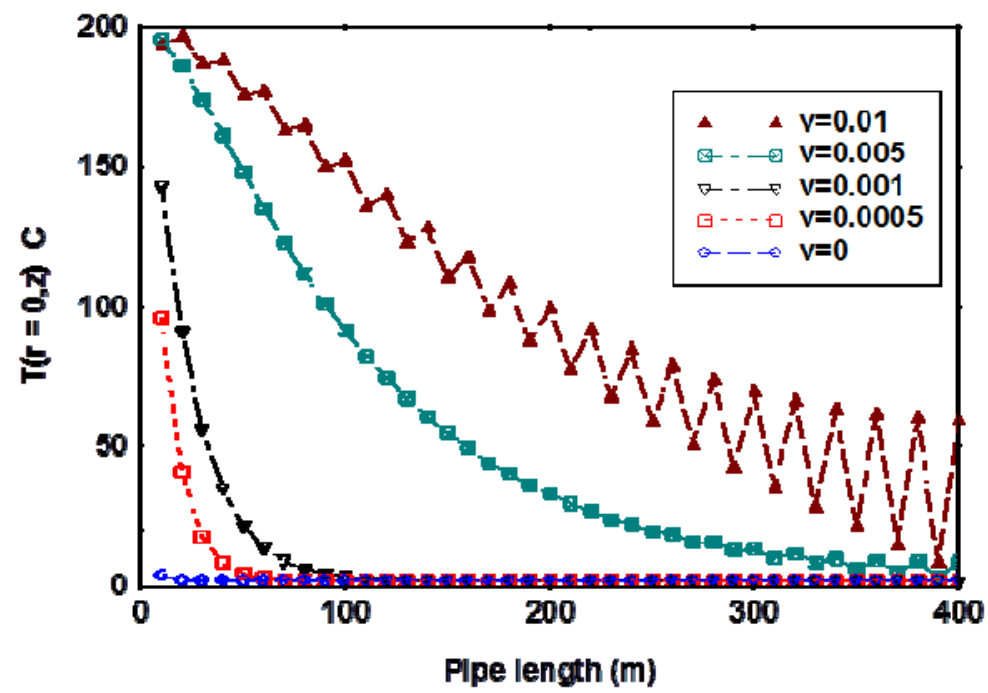

Figure 2: $\quad$ Temperature dependence along a $400 \mathrm{~m}$ long pipe of radius $0.5 \mathrm{~m}$ as the velocity of the water flowing along the pipe is increased.

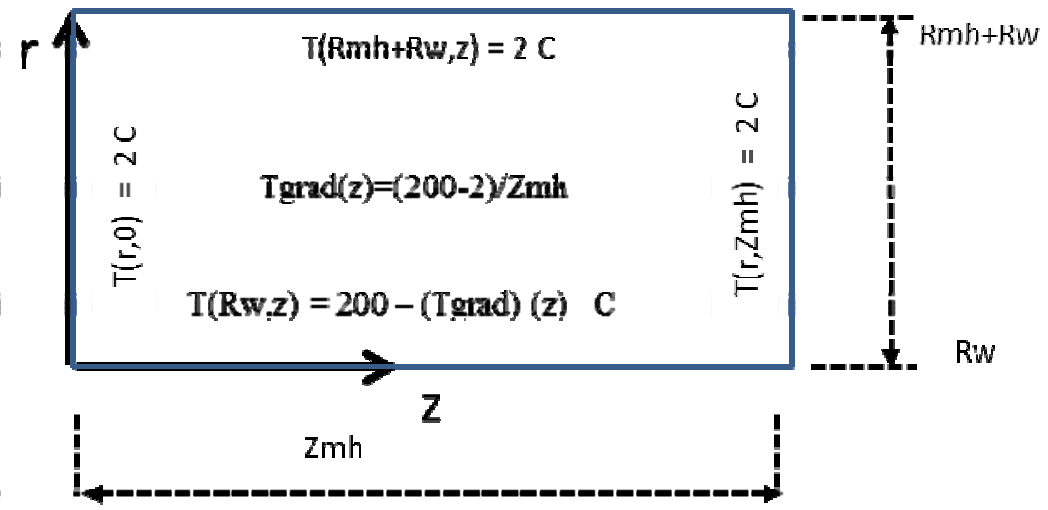

Figure 3: $\quad$ Boundary conditions for the reservoir volume.

This linear dependence of the temperature at the pipe surface will be the condition that we will use for the calculation of the temperature inside the methane hydrate reservoir. 


\section{Solutions inside the reservoir}

In Figure 3 we indicate show the geometry used in the model and the boundary conditions applied for the calculation of the melted volumes of methane hydrates. The temperature of the water at the entrance of the well is taken to be $200 \mathrm{C}$, and the reservoir is at an initial temperature of $2 \mathrm{C}$.

Inside the reservoir we find the temperature $\mathrm{T}(\mathrm{r}, \mathrm{z}, \mathrm{t})$ as the methane hydrate melts when the temperature exceeds the melting temperature of $\mathrm{Tm}=20 \mathrm{C}$. This melting implies a moving boundary problem. This moving boundary heat transfer problem (a Stefan problem) involving phase changes can be solved exactly only for an infinite sample according to Özisic [8]. The present finite volume problem can be solved numerically by several special heat transfer methods outlined by Chun-Pyo [9]. In this paper we have selected the enthalpy method for solving the two-dimensional numerical scheme for the geometry considered. In Figure 4 we show the enthalpy-temperature diagram that we have used for the methane hydrate melting transition.

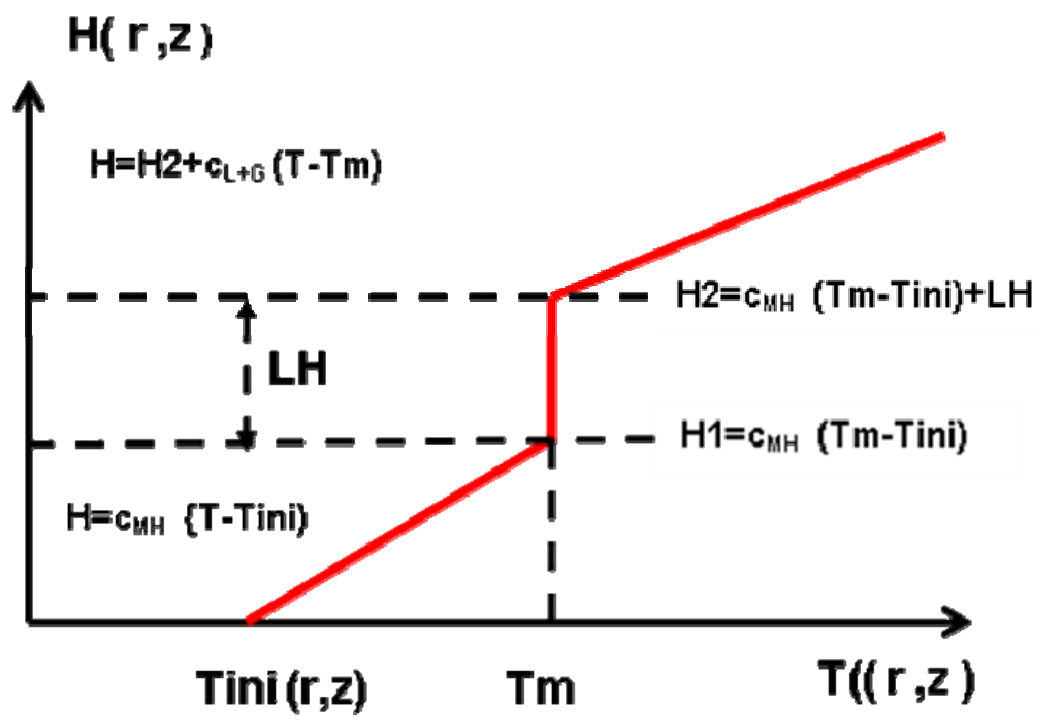

Figure 4: The enthalpy-temperature diagram.

In terms of the thermal conductivity $K$ (joules $/(\mathrm{m} \mathrm{K} \mathrm{sec})$ ), the density $\rho$ $\left(\mathrm{kg} / \mathrm{m}^{3}\right)$, and the specific heat at constant pressure $\mathrm{c}_{\mathrm{p}}$ (joules/(Kg K)). we can rewrite equs 1 and 2 as:

$$
\mathrm{K}\left[\frac{\partial^{2} \mathrm{~T}(\mathrm{r}, \mathrm{z})}{\partial \mathrm{r}^{2}}+\frac{1}{\mathrm{r}} \frac{\partial \mathrm{T}(\mathrm{r}, \mathrm{z})}{\partial \mathrm{r}}+\frac{\partial^{2} \mathrm{~T}(\mathrm{r}, \mathrm{z})}{\partial \mathrm{z}^{2}}\right]=\rho \mathrm{c}_{\mathrm{p}} \frac{\partial \mathrm{T}(\mathrm{r}, \mathrm{z})}{\partial \mathrm{t}}
$$


The enthalpy $\mathrm{H}$ is defined as:

$$
\mathrm{H}(\mathrm{r}, \mathrm{z}, \mathrm{t})=\int_{\text {Tini }}^{\mathrm{T}} \mathrm{c}_{\mathrm{p}} \mathrm{dT}=\mathrm{c}_{\mathrm{p}} \int_{\text {Tini }}^{\mathrm{T}} \mathrm{dT}=\mathrm{c}_{\mathrm{p}}[\mathrm{T}(\mathrm{r}, \mathrm{z}, \mathrm{t})-\operatorname{Tini}(\mathrm{r}, \mathrm{z})]
$$

where Tini(r, $\mathrm{z})$ is some initial temperature and $\mathrm{c}_{\mathrm{p}}$ is assumed to be constant. Thus in terms of the enthalpy, eqn (7) becomes:

$$
\mathrm{K}\left[\frac{\partial^{2} \mathrm{~T}(\mathrm{r}, \mathrm{z}, \mathrm{t})}{\partial \mathrm{r}^{2}}+\frac{1}{\mathrm{r}} \frac{\partial \mathrm{T}(\mathrm{r}, \mathrm{z}, \mathrm{t})}{\partial \mathrm{r}}+\frac{\partial^{2} \mathrm{~T}(\mathrm{r}, \mathrm{z}, \mathrm{t})}{\partial \mathrm{z}^{2}}\right]=\rho \frac{\partial \mathrm{H}(\mathrm{r}, \mathrm{z}, \mathrm{t})}{\partial \mathrm{t}}
$$

When we discretize in space and in time eqn (9) becomes:

$$
\left[\frac{T_{i+1, j}^{k}-2 T_{i, j}^{k}+T_{i-1, j}^{k}}{(\Delta r)^{2}}+\frac{T_{i+1, j}^{k}-T_{i, j}^{k}}{i(\Delta r)^{2}}+\frac{T_{i, j+1}^{k}-2 T_{i, j}^{k}+T_{i, j-1}^{k}}{(\Delta z)^{2}}\right]=\frac{\rho(i, j)}{K(i, j)} \frac{H_{i, j}^{k+1}-H_{i, j}^{k}}{\Delta t}
$$

The values of $K$ and $\rho$ will correspond to the values for methane hydrate or water (or a combination of both) according to the state of adjacent volume elements. The iteration according to the enthalpy method proceeds as follows:

1) $T_{i, j}^{k}(r, z)$ the initial temperature is set to $2 \mathrm{C}$, except at the well nodes

2) $\mathrm{H}_{\mathrm{i}, \mathrm{j}}^{\mathrm{k}}$ is arbitrarily chosen as zero

3) $\mathrm{H}_{\mathrm{i}, \mathrm{j}}^{\mathrm{k}+1}$ is found from eqn(10)

4) The new temperature at each point is determined in accordance with the enthalpy diagram of Figure 4

The values used for the different material properties taken from Gupta et al. [10] and Waite et al. [11] are:

for methane hydrates: latent heat $=438540$ (joules $/ \mathrm{kg}$ ), specific heat $=2108$ joules $/(\mathrm{kg} \mathrm{K})$, density $=913 \mathrm{~kg} /\left(\mathrm{m}^{3}\right)$, and thermal conductivity $=0.5 \mathrm{watts} /(\mathrm{m} . \mathrm{K})$ for water: specific heat $=4187$ joules $/(\mathrm{kg} . \mathrm{K})$, density $=1000 \mathrm{~kg} /\left(\mathrm{m}^{3}\right)$, and thermal conductivity $=0.58$ watts $/(\mathrm{m} . \mathrm{K})$

The temperature of the incoming water is set at $200 \mathrm{C}$, a reasonable value for combined cycle heat exchangers (Horlock [12] and thus the temperature of the water produced by the melting of the methane hydrates will always be insufficient to vaporize the water. At depths of 1000 meters the pressure is close to $10^{7}$ Pascals corresponding to a temperature of evaporation of some $300 \mathrm{C}$. The only gas produced is methane.

\section{Energy efficiency}

The energy applied to the reservoir is the kinetic energy of the applied hot water, flowing at a velocity $\mathrm{v}(\mathrm{m} / \mathrm{sec})$ at a time $\mathrm{t}$ :

$$
\mathrm{E}_{\text {in }}=0.5 \rho_{\mathrm{w}}\left(\mathrm{r}_{\mathrm{w}}\right)^{2} \mathrm{z}_{\mathrm{MH}}(\mathrm{v})^{2} \mathrm{t}
$$

The energy output is given by the equivalent energy corresponding to the volumes of methane hydrate that melt at $20 \mathrm{C}$ in different parts of the reservoir. 
This equivalent energy is taken to be of the order of $6.1 \times 10^{9}$ joules for each cubic meter of methane hydrate. We reach this amount in the following manner:

a) 1 cubic meter of methane hydrate yields 160-170 cubic meters of methane at standard temperature and pressure (at STP of $0 \mathrm{C}$ and $1 \mathrm{~atm}$ )

b) Measurements of the heat of combustion of methane by Dale et al. [13], yield a value of $8.906 \times 10^{5}$ joules/mol corresponding to $3.868 \times 10^{7}$ joules $/ \mathrm{m}^{3}$ of methane. This value closely agrees with an energy content in the range of $1.86 \times 10^{7}$ to $4.59 \times 10^{7}$ joules $/ \mathrm{m}^{3}$ reported in the literature for natural gas by Speight [14].

c) Thus 1 cubic meter of methane hydrate producing $160 \mathrm{~m}^{3}$ of methane gas yields an equivalent energy of $6.1 \times 10^{9}$ joules.

In the following figures we show the results for the energy input vs. time, as well as the net energy produced by heating the methane hydrate reservoir. We also show the results for the energy efficiency of the process, as given by the ratio of the energy liberated to the energy applied.

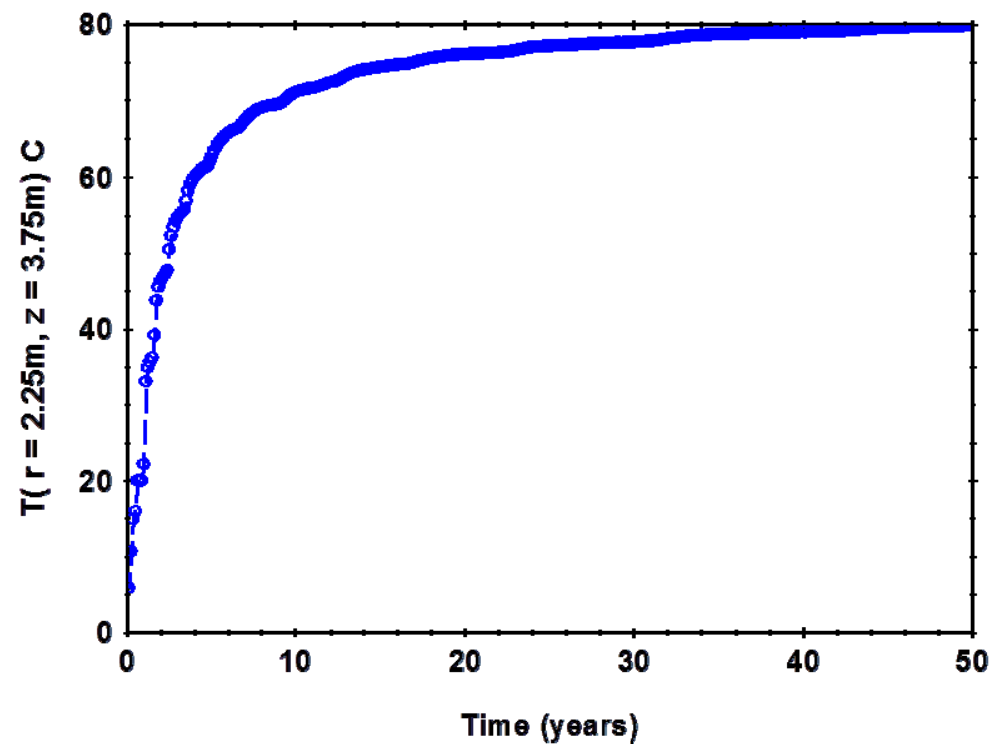

Figure 5: The temperature at a given point inside the reservoir vs. time.

The figure clearly shows the nature of the temperature dependence at a given point inside the reservoir as the different reservoir volumes will melt. Figure 6 shows the linear time dependence of the applied energy corresponding to a constant applied power as well as the energy produced by the melting of the methane hydrate reservoir. 


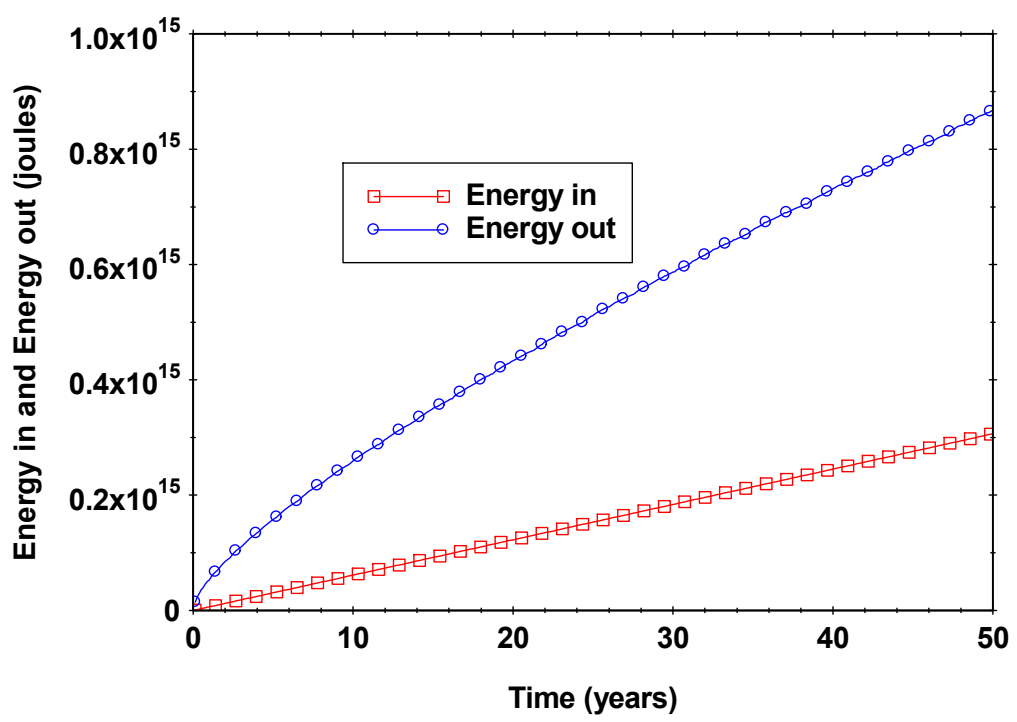

Figure 6: Applied and produced energy vs. time.

Figure 7 shows the EROI of the process, the ratio energy out to energy in.

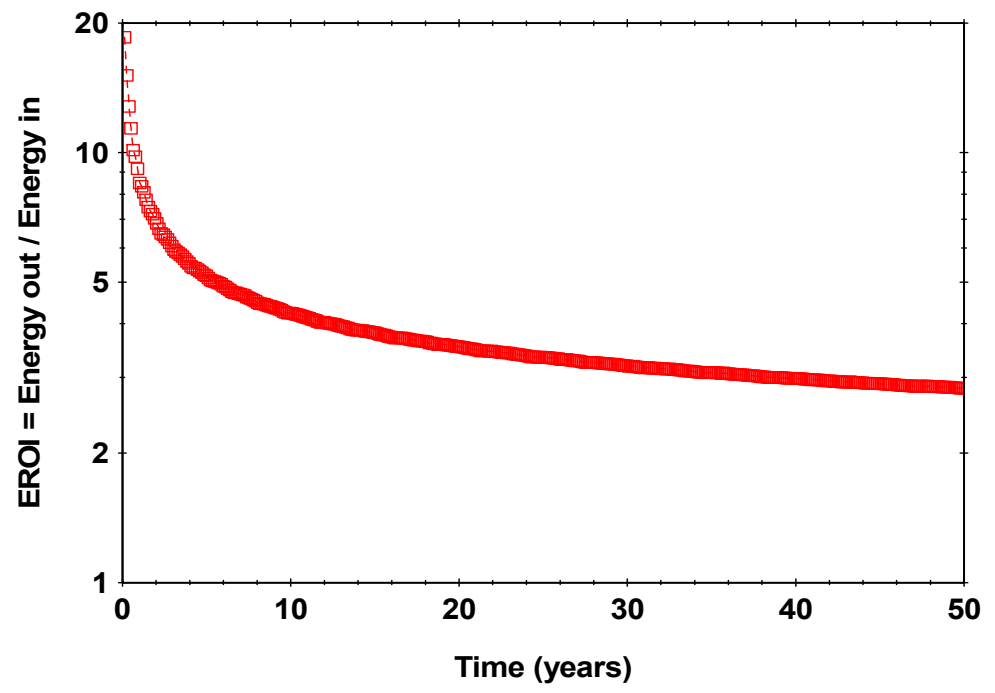

Figure 7: $\quad$ EROI vs. time. 


\section{Conclusions}

We have determined the response of seabed methane hydrate deposits under the thermal excitation of hot water flowing along a well located at the center of a reservoir. When only the kinetic energy associated to the hot water flow is considered as input energy, significant energy gains are calculated. EROI factors begin at 28 as the water starts flowing, and reduce to a value of 2.8 after fifty years of production. We have not considered the energy required to heat up the water in the well as we assume that this hot water is the available output of heat exchangers for a floating co-generation plant contemplated in the Japanese scheme for methane hydrate deposits in the Nankai trough as reported by Yamakawa et al. [4]. The partial EROI that we have calculated is significantly above unity, thus showing that hot water excitation of methane hydrate deposits represent a potentially valid production scheme. If the partial EROI that we determined in this paper had been less than unity this kind of production scheme would be useless.

\section{References}

[1] Sloan E.D. Clathrate Hydrates of Natural Gases; Marcel Dekker Inc.: New York, NY, USA, 1998.

[2] Carroll, J. Natural gas Hydrates, 2nd ed.; Elsevier: Oxford, UK, 2009.

[3] Demirbas, A. Biohydrogen: For Future Engine Fuel Demands; SpringerVerlag: London, UK, 2009.

[4] Yamakawa, T., Ono S., Iwamoto A., Sugai Y., and Sasaki K.; A Gas Production System From Methane Hydrate Layers By Hot Water Injection And BHP Control With Radial Horizontal Wells. SPE paper 137801. In Proceedings of the Canadian Unconventional Resources and International Petroleum Conference, CURIPC 10, Calgary, Alberta, Canada, 19-21 October 2010; Society of Petroleum Engineers: Houston, TX, USA.

[5] Callarotti, R.C., Electromagnetic heating of oil, in SPE Handbook of Petroleum Engineering Vol.6; Chapter 12, Lake, L., Ed., Society of Petroleum Engineers: Houston, TX, USA, 2007; Volume 6, pp. 567-609.

[6] Callarotti, R.C. Energy Efficiency In The Electrical heating Of Methane Hydrate Reservoirs. SPE paper 137585. In Proceedings of the Canadian Unconventional Resources and International Petroleum Conference, CURIPC 10, Calgary, Alberta, Canada, 19-21 October 2010; Society of Petroleum Engineers: Houston, TX, USA.

[7] Callarotti R.C. Energy return on energy invested (EROI) for the electrical heating of methane hydrate reservoirs, Sustainability, 2011, 3, 2105-2114; doi:10.3390/su3112105.

[8] Özisic N., Heat Conduction, Wiley Interscience, New York, 1980.

[9] Chun-Pyo, H. Computer Modeling of Heat and Fluid Flow in Materials Processing; Institute of physics printing: Bristol, UK, 2004. 
[10] Gupta, A. Lachance, J.; Sloan, E.D.; Koh, C.A. Measurements of methane hydrate heat of dissociation using high pressure differential scanning calorimetry. Chem. Eng. Sci. 2008, 63, 5848-5853.

[11] Waite, S.F. Stern, L.A.; Kirby, S.H.; Winters, W.J. ; Mason, D.H. Simultaneous determination of thermal conductivity, thermal diffusivity and specific heat in sI methane hydrate. Geophys. J. Int. 2007, 169, 767774.

[12] Horlock, J.H., Cogeneration-Combined Heat and Power (CHP), Reprint Edition, Krieger Publishing Co., Malabar (Florida), 1997, 179.

[13] Dale, A.; Lythall, C.; Aucott, J.; Sayer, C. High precision calorimetry to determine the enthalpy of combustion of methane. Thermochim. Acta 2002, 382, 47-54.

[14] Speight, J.G. Synthetic Fuel Handbook; McGraw Hill: New York, NY, USA, 2008, page 40. 